\title{
Carpal tunnel syndrome: evaluation of its provocative clinical tests
}

\author{
Ahmed A. Arab, Mohamed M. Elmaghrabi and Mohamed H. Eltantawy
}

\begin{abstract}
Background: The diagnosis of carpal tunnel syndrome (CTS) is established mainly on a clinical basis, and diagnosis is done after careful history taking and examination including known provocative tests with varying efficacy and reliability.

Methods: A prospective clinical study of 123 patients with 171 hands presenting with classical symptoms of carpal tunnel syndrome were included in this study, from October 2013 to October 2015, and they underwent open surgical release of flexor retinaculum at the Neurosurgery Department of Benha University Hospital.

Results: ART is positive in $88.3 \%$. This is compared to $75,81.3,79.7$, and $83.6 \%$ of positive results in Tinel's test, compression test, Phalen's test, and combined Phalen's and compression test. ART is the most sensitive and specific test and has the highest positive predictive value of $98.3 \%$, negative predictive value of $81.9 \%$, and accuracy of $91.4 \%$.

Conclusion: ART is a simple, reliable, and easily performed test for evaluating carpal tunnel syndrome; it is superior to other tests and could be used also to assess improvement after surgery.
\end{abstract}

Keywords: Carpal tunnel syndrome, Arm raising test, Provocative tests

\section{Background}

The diagnosis of carpal tunnel syndrome (CTS) is established mainly on a clinical basis, and diagnosis is done after careful history taking and examination including known provocative tests with varying efficacy and reliability.

Electrodiagnostic studies are used to confirm diagnosis and some studies discourage its use as an exclusive tool [1], but other studies had refined the technique and data analysis to establish a dependable and reliable diagnosis [2].

Reliability of provocative tests in CTS was and still being studied; these tests depends on the examiners and how they are performing it, it is so that it differs from general practitioner to experts in yielding true results helpful for diagnosis [3].

Arm raising test was first described in 2001 [4] and was studied by other authors $[5,6]$. It is not depending on the examiner as it is not done with their hand but

\footnotetext{
*Correspondence: dr_elmaghrabi@yahoo.com;

mohamed.almaghreby01@fmed.bu.edu.eg

Department of Neurosurgery, Benha University, 78th elshoban elmosImin, Benha, Qualiobih, Egypt
}

(c) The Author(s). 2018 Open Access This article is distributed under the terms of the Creative Commons Attribution 4.0 International License (http://creativecommons.org/licenses/by/4.0/), which permits unrestricted use, distribution, and reproduction in any medium, provided you give appropriate credit to the original author(s) and the source, provide a link to the Creative Commons license, and indicate if changes were made. only with an order to the patients and receiving their comment once symptoms are recognized.

This is a prospective clinical study of 123 patients with 171 hands presenting with classical symptoms of carpal tunnel syndrome who were included in this study, from October 2013 to October 2015, and they underwent open surgical release of flexor retinaculum at the Neurosurgery Department of Benha University Hospital.

\section{Objective}

We aim to compare this test to commonly used provocative tests, and to confirm its reliability in diagnosing CTS and evaluating improvement after carpal tunnel release surgery.

\section{Preoperative work-up}

One hundred twenty-three patients with 171 hands presented with classical symptoms of carpal tunnel

\section{Methods \\ Study design} \\ Springer Open}


syndrome, with pain and numbness that worsened with exertion and at night in the distribution of medial nerve, and with positive nerve conduction studies (NCS) and electromyography results suggesting median nerve entrapment. Patients who had symptoms and signs of a proven diagnosis of cervical radiculopathy and other upper limb entrapment neuropathy were excluded, also patients with diabetes, thyroid disease, peripheral neuropathy, and peripheral vascular disease were excluded; hence, 18 patients were excluded leaving 105 patients with 128 hands; of them, 23 patients had bilateral disease.

The control group consists of 35 patients with 70 hands, and NCS were not conducted in this group, but same exclusion criteria were applied.

History was standardized by using K-S questionnaire for both groups in which a score of 50 or more was considered clinically diagnostic of CTS [7].

Provocative tests were performed in a sequence with a 1-min interval between each test, then tests were done with an examiner using only a single hand as in Table 1.

\section{Operative note}

Under local or general anesthesia, without tourniquet, decompression of median nerve at wrist was done by complete cutting of the flexor retinaculum. No complications were reported.

\section{Post-operative follow-up}

Provocative tests were performed again, by the same examiner, in a sequence with a 1-min interval between each test (Table 1) in 3, 6, and 9 months.

\section{Statistical analysis:}

SPSS software (Version 20.0 for Windows, SPSS Inc., Chicago, IL) was used for analyses of the data. Qualitative variables were summarized as frequency and percentages. McNemar test was used to compare the follow-up periods. Validity of tests was tested using sensitivity, specificity, positive predictive value (PPV), negative predictive value (NPV), and accuracy. Differences were considered significant at $P \leq 0.05$ and insignificant at $P>0.05$.

\section{Results}

In our study, ART is positive in $88.3 \%$ (113 out of 128 hands with evident carpal tunnel syndrome). This is compared to $75,81.3,79.7$, and $83.6 \%$ of positive results in Tinel's test, compression test, Phalen's test, and combined Phalen's and compression test. Also in the control group, only 2 hands out of 70 have a positive ART (2.9\%). This is compared to $18.6,15.8,11.4$, and $22.8 \%$ of positive results in Tinel's test, compression test, Phalen's test, and combined Phalen's and compression test. As shown in Table 2, ART is the most sensitive and specific test and has the highest positive predictive value of $98.3 \%$, negative predictive value of $81.9 \%$, and accuracy of $91.4 \%$.

Postoperatively at 9 months, 5 out of the 128 (3.9\%) hands have a positive ART, 3 of them had recurrent milder symptoms. Table 3 shows that 6.3, 5.5, 5.5, and 7\% have positive Tinel's test, Phalen's test, compression test, and Phalen's + compression test respectively at 9 months; however, these numbers are $14.1,13.3,10.9$, and $14.1 \%$ at 3 months postoperatively in contrast to $3.1 \%$ of ART which is statistically significant.

\section{Discussion}

Carpal tunnel syndrome is usually diagnosed in a clinical basis; after taking history that suggests the condition, common provocative easy tests as Phalen's and Tinel's tests are usually used to ascertain the diagnosis. Electrodiagnostic studies are routinely used in our department before a decision for surgery is employed. Meticulous history and physical examination are usually sufficient to have a sure clinical diagnosis of CTS and make initial treatment decisions. However, electrodiagnostic studies can confirm the clinical impression of CTS, which is reassuring for both the patient and physician [2].

Sensitivity and specificity of Tinel's and Phalen's tests were variable in different studies (Tinel's test had a sensitivity of $48-77 \%$ and a specificity of $47-84 \%$, and Phalen's test had a sensitivity of $28-61 \%$ and a specificity of $80-94 \%$ ) [8]. This difference in results may be due to the fact that these tests depend on the way they are

Table 1 Methods of performing tests and its positive finding

\begin{tabular}{|c|c|c|}
\hline Test & Method & Positive finding \\
\hline Tinel's test & $\begin{array}{l}\text { Percussion the area over and proximal to flexor retinaculum } \\
\text { gently using the rubber hammer }\end{array}$ & $\begin{array}{l}\text { Numbness or electric like sensation felt beneath } \\
\text { or on the hand }\end{array}$ \\
\hline Phalen's test & Flexing the wrist at $90^{\circ}$ in unforced manner & Reproduction of symptom within 1 min \\
\hline Compression test & Compressing over the flexor retinaculum & Reproduction of symptom within 1 min \\
\hline Phalen's + compression test & $\begin{array}{l}\text { Compressing over the flexor retinaculum while flexing the } \\
\text { wrist to the maximum affordable with compression }\end{array}$ & Reproduction of symptom within 1 min \\
\hline Arm raising test & Raising whole arm straight above the head & Reproduction of symptom within $1 \mathrm{~min}$ \\
\hline
\end{tabular}


Table 2 Preoperative provocative tests results among case and control groups

\begin{tabular}{|c|c|c|c|c|c|c|c|c|}
\hline \multirow[t]{2}{*}{ Test and test result } & & \multicolumn{2}{|l|}{ Studied groups } & \multirow[t]{2}{*}{ Sensitivity } & \multirow[t]{2}{*}{ Specificity } & \multirow[t]{2}{*}{ PPV } & \multirow[t]{2}{*}{ NPV } & \multirow[t]{2}{*}{ Accuracy } \\
\hline & & Case group (128) & Control group (70) & & & & & \\
\hline \multirow[t]{2}{*}{ Tinel's } & + ve & $96(75.0)$ & 13(18.6) & $75 \%$ & $81.4 \%$ & $88 \%$ & $64 \%$ & $77.3 \%$ \\
\hline & $-v e$ & $32(25.0)$ & $57(81.4)$ & & & & & \\
\hline \multirow[t]{2}{*}{ Compression } & + ve & 104(81.3) & 11(15.8) & $81.3 \%$ & $84.2 \%$ & $90.4 \%$ & $71.1 \%$ & $82.3 \%$ \\
\hline & $-v e$ & $24(18.7)$ & $59(84.2)$ & & & & & \\
\hline \multirow[t]{2}{*}{ Phalen's } & + ve & 102(79.7) & $8(11.4)$ & $79.7 \%$ & $88.6 \%$ & $92.7 \%$ & $70.4 \%$ & $82.8 \%$ \\
\hline & $-v e$ & $26(20.3)$ & $62(88.6)$ & & & & & \\
\hline \multirow[t]{2}{*}{ Phalen's + compression } & + ve & 107(83.6) & $16(22.9)$ & $83.6 \%$ & $77.1 \%$ & $87 \%$ & $72 \%$ & $81.3 \%$ \\
\hline & $-v e$ & $21(16.4)$ & $54(77.1)$ & & & & & \\
\hline \multirow[t]{2}{*}{ ART } & + ve & 113(88.3) & $2(2.9)$ & $88.3 \%$ & $97.1 \%$ & $98.3 \%$ & $81.9 \%$ & $91.4 \%$ \\
\hline & $-v e$ & 15(11.7) & 68(97.1) & & & & & \\
\hline
\end{tabular}

performed, and this varied between examiners [5]. Tinel's test was described as a non-useful test in comparison to Phalen's in diagnosing CTS [9].

And others suggested combining results of both Tinel's and Phalen's tests to obtain up to $90 \%$ sensitivity $[10,11]$.

In this study, Phalen's test was done as usual with flexion of the wrist to $90^{\circ}$ in an unforced manner, but we performed Tinel's test using gentle percussion using a rubber hammer to uniform the shape and force of the percussion tip. However, compression test had some personal variety as some of our patients had delicate hands easily compressed and others had tough hands especially manual workers.

Patients usually experienced pain in hand elevation position such as holding mobile to the ear, combing their hair, writing on a board, and painting of ceilings. In the arm raising test, it is done only by giving an instruction to the patient. It is an easy test to perform, no equipment needed or examiner work. However, the arm raising test may be difficult in patients with shoulder problem, and it may aggravate a thoracic outlet syndrome, but in this condition, symptoms are produced along the ulnar side [5].

ART was found to have a sensitivity of $76 \%$ and a specificity of $99 \%$ in one report [4]; in another report, sensitivity and specificity were 88 and $98 \%$ respectively [5]; and another study reported sensitivity as $98.6 \%$ and specificity as $91.4 \%$ [6]. In these studies, the arm raising test was superior to other clinical tests [4-6] and even reported to be comparable to a combination of four clinical provocative tests [6]. In our study, it had a sensitivity of $88.3 \%$ and specificity of $97.1 \%$. Also results of our study are comparable to these studies as regards positive and negative predictive values.

So it was also clear in our study that the arm raising test provides the best contribution to the diagnosis of CTS, adding to its simplicity.

ART and Phalen's test were found superior to Tinel's test in postoperative evaluation [5]. Our study following the patients postoperatively at 3,6 , and 9 months showed that ART is superior to all tests in detecting improvement followed by Phalen's and compression tests. Tinel's test should not be used to assess early improvement.

\section{Conclusions}

Arm raising test is a simple, reliable, and easily performed test for evaluating carpal tunnel syndrome; it is superior to other tests and could be used also to assess improvement after surgery. We recommended its use as a valid clinical test.

Table 3 Pre- and postoperative tests results among case group

\begin{tabular}{|c|c|c|c|c|c|c|}
\hline & & ART (128) & Tinel's (128) & Phalen's (128) & Compression (128) & $\begin{array}{l}\text { Phalen's + } \\
\text { compression (128) }\end{array}$ \\
\hline Preoperative & & $113(88.3)$ & $96(75.0)$ & $102(79.7)$ & $103(80.5)$ & 107 (83.6) \\
\hline \multirow[t]{3}{*}{ Postoperative } & 3 months & $4(3.1)$ & $18(14.1)$ & $17(13.3)$ & $14(10.9)$ & $18(14.1)$ \\
\hline & 6 months & $4(3.1)$ & $12(9.4)$ & $10(7.8)$ & $9(7.0)$ & $12(9.4)$ \\
\hline & 9 months & $5(3.9)$ & $8(6.3)$ & $7(5.5)$ & $7(5.5)$ & $9(7.0)$ \\
\hline$P$ value & & $0.001^{*}$ & $0.001^{*}$ & $0.001^{*}$ & $0.001^{*}$ & $0.001^{*}$ \\
\hline
\end{tabular}

*Significant at $<0.05$ 


\section{Abbreviations}

ART: Arm raising test; CTS: Carpal tunnel syndrome; NCS: Nerve conduction studies

\section{Acknowledgements}

The authors thank all patients who accept participation in this study.

\section{Availability of data and materials}

The data supporting our findings can be found with the corresponding author and can be contacted through the following e-mails: dr_elmaghrabi@yahoo.com, mohamed.almaghreby01@fmed.bu.edu.eg

\section{Authors' contributions}

AAA gave idea and performed the clinical provocative tests, pre- and postoperatively, of the study. MME and MHE put study design and analyzed the data. AAA and MME wrote with meticulous revision of the paper and approved the final version of the manuscript. All authors read and approved the final manuscript.

\section{Ethics approval and consent to participate}

This research accepted by Research Ethics Committee (REC) of the Faculty of Medicine, Benha University (chairman: Prof/lbrahim El-Gendy).

All procedures performed in studies involving human participants were in accordance with the ethical standards of the institutional and/or national research committee and with the 1964 Helsinki Declaration and its later amendments or comparable ethical standards. A written informed consent was obtained from each patient after explaining all steps of this study. The reference number of the ethics approval from the ethics committee: $F$ 10, serial number 80 . For any details please contact responsible person: Professor Dr. Nermeen Adly, telephone: + 201,000,071,033, e-mail: nmadly1@hotmail.com.

\section{Consent for publication}

Not applicable, as there were no identifiable data of patients.

\section{Competing interests}

The authors declare that they have no competing interests.

\section{Publisher's Note}

Springer Nature remains neutral with regard to jurisdictional claims in published maps and institutional affiliations.

Received: 29 August 2017 Accepted: 24 June 2018

Published online: 13 August 2018

\section{References}

1. Louis D, Hankin F. Symptomatic relief following carpal tunnel decompression with normal electroneuromyographic studies. Orthopedics. 1987:10:434.

2. Werner RA, Andary M. Electrodiagnostic evaluation of carpal tunnel syndrome. Muscle Nerve. 2011:44(4):596-607.

3. Marx RG, Hedak PL, Bombardier C, Graham B, Goldsmith C, Wright JG. The reliability of physical examination for carpal tunnel syndrome. J Hand Surg. 1998;23B:499-502.

4. Ahn DS. Hand elevation: a new test for carpal tunnel syndrome. Ann Plast Surg. 2001:46:120-4.

5. Amirfeyz R, Gozzard C, Leslie IJ. Hand elevation test for the evaluation of carpal tunnel syndrome. J Hand Surg. 2005;30:361-4.

6. Amirfeyz R, Clark D, Parsons B, Melotti R, Bhatia R, Leslie I, Bannister J. Clinical tests for carpal tunnel syndrome in contemporary practice. Arch Orthop Trauma Surg. 2011;131:471-4.

7. Kamath V, Stothard J. A clinical questionnaire for the diagnosis of carpal tunnel syndrome. J Hand Surg (Br). 2003;28(5):455-9.

8. Gonzalez DJ, Delgado-Matinez AD, Gonzalez I, Lovic A. Value of the carpal compression test in the diagnosis of carpal tunnel syndrome. J Hand Surg (Br). 1997;22:38-41.

9. Kuschner SH, Ebramzadeh E, Johnson D, et al. Tinel's sign and Phalen's test in carpal tunnel syndrome. Orthopedics. 1992;15:1297-302.

10. Seror P. Phalen's test in the diagnosis of carpal tunnel syndrome. J Hand Surg (Br). 1988;13:383.

11. Kanz J, Larson M, Fossel $\mathrm{A}$, et al. Validation of a surveillance case definition of carpal tunnel syndrome. Am J Public Health. 1991;81:189.

\section{Submit your manuscript to a SpringerOpen ${ }^{\circ}$ journal and benefit from:}

- Convenient online submission

- Rigorous peer review

- Open access: articles freely available online

- High visibility within the field

- Retaining the copyright to your article

Submit your next manuscript at $\boldsymbol{\nabla}$ springeropen.com 